\title{
A Rare Case of Hyperglycemic-Hemichorea in a Young Patient
}

\author{
Meraj Fatima ${ }^{1}$, Mohsin Iqbal ${ }^{2,3}$, Saira Abbas ${ }^{4}$, Deepak Kumar ${ }^{5}$, FNU Jitidhar 6
}

1. Neurology, Dow International Medical College, Dow University Hospital, Dow University of Health Sciences, Karachi, PAK 2. Internal Medicine, Dow University of Health Sciences, Karachi, PAK 3. Internal Medicine, Dow University Hospital, Karachi, PAK 4. Neurology, Dow University of Health Sciences, Karachi, PAK 5. Internal Medicine: Nephrology, Jinnah Postgraduate Medical Center, Karachi, PAK 6. Internal Medicine, Dow Medical College/ Civil Hospital, Karachi, PAK

Corresponding author: Meraj Fatima, dr.merajfatima@hotmail.com

\begin{abstract}
Chorea is an abnormal, nonrhythmic, and purposeless movement of limbs. There is a long list of diseases responsible for chorea; long-standing hyperglycemia can sometimes result in it, which typically manifests on one side of the body. MRI brain is an added diagnostic tool, which commonly shows hyperintense basal ganglia lesion on T1-weighted images. Chorea in the context of hyperglycemia is a reversible and infrequent occurrence, best managed with insulin and haloperidol combination therapy. Here, we discuss a patient with hyperglycemic-hemichorea, whose symptoms resolved completely within two months of taking insulin and haloperidol.
\end{abstract}

Categories: Internal Medicine, Neurology

Keywords: chorea, hyperglycemic hemichorea, chorea hyperglycemia basal ganglia syndrome

\section{Introduction}

Chorea is a rapid, involuntary, abnormal, and irregular movement of limbs, which can involve trunk, head, and neck occasionally. There are a variety of conditions resulting in chorea: cerebrovascular insult, hormone replacement therapy, L-Dopa, Huntington's disease, thyroid disorder, Wilson's disease, poststreptococcal Sydenham's chorea, and autoimmune conditions are some examples. But these disorders cause bilateral symptoms most of the time [1]. Hemichorea is an infrequent, but reversible presentation associated with hyperglycemia [2]. It can be treated with correction of hyperglycemic state within two to 28 days on average [3]. Here, we present a young patient with left-sided hemichorea, diagnosed with hyperglycemia as a causative factor.

\section{Case Presentation}

A 30-year-old South Asian male with no known co-morbid, presented with the complaints of involuntary, abrupt, and purposeless movement of left upper and lower limbs along with difficulty walking for two weeks, but could ambulate without assistance. These movements suppressed partially by rest, and disappeared completely during sleep but aggravated on performing tasks. The patient did not have urinary or stool incontinence. History of undocumented, unintentional weight loss was present, noticed due to the loosening of clothes. On detailed questioning, he denied a history of head trauma, tongue bite, unconsciousness, memory impairment, neuropsychiatric symptoms, fever, sore throat, heat intolerance, joints pain, oral ulcers, photosensitivity, or jaundice. Past medical, surgical, or history of blood transfusion was not significant. He declined the use of illicit drugs or any antipsychotic medications. His father was diabetic and hypertensive. There was no history of similar illness in family members. His sleep, appetite, bowel habits were normal, but noticed an increase in the frequency of passing urine lately.

Higher mental functions were intact. Mini-mental state examination revealed intact cognitive function. Pupils were bilaterally equal and reactive to light and no Kayser-Fleischer ring appreciated on naked eye examination. Cranial nerves were intact, muscle mass was normal, power five/five in all limbs. Deep tendon reflexes and the sensory system were intact, while planters were bilaterally flexors. Cerebellar signs were negative, whereas gait was abnormal due to hyperkinetic dance-like movements. Milk Maid grip sign and pronator sign were positive on the left side. We could not assess Romberg's sign. All other systemic examinations were within normal limits.

Random blood sugar was $453 \mathrm{mg} / \mathrm{dL}$, while HbA1c 15.13\% on patient presentation. We have presented blood/serum laboratory reports in Table 1. Arterial blood gas parameters were within normal limits on presentation. Urine analysis was insignificant with no ketones but positive glucosuria only. MRI brain with contrast showed right-sided basal ganglia hyperintense lesion in lentiform nucleus on T1 weighted images (Figure 1), but no ischemia or hemorrhages suggested. Hence, we diagnosed the patient with hyperglycemichemichorea (chorea-hyperglycemia-basal ganglia syndrome). We started our patient on insulin therapy along with haloperidol. His symptoms progressively improved and he was much better after 12 days of 


\section{Cureus}

starting therapy. He improved completely after 55 days. Blood glucose levels remained under control and repeat $\mathrm{HbA1c}$ after two months was $8.24 \%$.

\begin{tabular}{|c|c|c|}
\hline Blood/Serum investigation & Result & Reference range \\
\hline Hemoglobin & $11.8 \mathrm{~g} / \mathrm{dL}$ & $13.0-16.5 \mathrm{~g} / \mathrm{dL}$ \\
\hline MCV & $76 \mathrm{fL}$ & 80-100 fL \\
\hline White blood cells & $10.3 \times 10^{3} / \mathrm{uL}$ & $4.0-11.0 \times 10^{3} / \mathrm{uL}$ \\
\hline Platelets & $369 \times 10^{3} / \mathrm{uL}$ & $150-400 \times 10^{3} / \mathrm{uL}$ \\
\hline ESR & $15 \mathrm{~mm} / \mathrm{h}$ & Males: $0-15 \mathrm{~mm} / \mathrm{h}$ \\
\hline Urea & 29.3 mg/dL & 1/-49 mg/dL \\
\hline Creatinine & $0.93 \mathrm{mg} / \mathrm{dL}$ & $0.9-1.3 \mathrm{mg} / \mathrm{dL}$ \\
\hline Sodium & $130 \mathrm{mEq} / \mathrm{L}$ & 136-146 mEq/L \\
\hline Chloride & $92 \mathrm{mEq} / \mathrm{L}$ & 104-114 mEq/L \\
\hline Bicarbonate & $29 \mathrm{mEq} / \mathrm{L}$ & 23-29 mEq/L \\
\hline Potassium & $4.1 \mathrm{mEq} / \mathrm{L}$ & 3.5-5.1 mEq/L \\
\hline Calcium & $8.9 \mathrm{mg} / \mathrm{dL}$ & $18-50$ yrs: $8.8-10.2 \mathrm{mg} / \mathrm{dL}$ \\
\hline Magnesium & $2.0 \mathrm{mg} / \mathrm{dL}$ & Adult: $1.6-2.6$ mg/dL \\
\hline Phophorus & 3.8 mg/dL & Adults: $2.7-4.5$ mg/dL \\
\hline C-Reactive protein & $0.5 \mathrm{mg} / \mathrm{dL}$ & Less than $5 \mathrm{mg} / \mathrm{dL}$ \\
\hline Total bilirubin & $0.49 \mathrm{mg} / \mathrm{dL}$ & $0.2-1.2 \mathrm{mg} / \mathrm{dL}$ \\
\hline Direct bilirubin & $0.19 \mathrm{mg} / \mathrm{dL}$ & $0-0.3 \mathrm{mg} / \mathrm{dL}$ \\
\hline Indirect bilirubin & $0.3 \mathrm{mg} / \mathrm{dL}$ & $0.25-0.9 \mathrm{mg} / \mathrm{dL}$ \\
\hline SGPT (ALT) & $31 \mathrm{U} / \mathrm{L}$ & Less than $45 \mathrm{U} / \mathrm{L}$ \\
\hline SGOT (AST) & $29 \mathrm{U} / \mathrm{L}$ & Less than $35 \mathrm{U} / \mathrm{L}$ \\
\hline Alkaline phosphatase & $124 \mathrm{U} / \mathrm{L}$ & 53-124 U/L \\
\hline GGT & $40 \mathrm{U} / \mathrm{L}$ & Less than $55 \mathrm{U} / \mathrm{L}$ \\
\hline Triglyceride & 234 mg/dL & Less than $150 \mathrm{mg} / \mathrm{dL}$ \\
\hline Cholesterol & $243 \mathrm{mg} / \mathrm{dL}$ & Less than $200 \mathrm{mg} / \mathrm{dL}$ \\
\hline HDL & 48 mg/dL & $40-60 \mathrm{mg} / \mathrm{dL}$ \\
\hline LDL & 167 mg/dL & Less than $100 \mathrm{mg} / \mathrm{dL}$ optimal \\
\hline VLDL & 47 mg/dL & Less than $30 \mathrm{mg} / \mathrm{dL}$ \\
\hline TSH & $1.83 \mathrm{mlU} / \mathrm{mL}$ & Adult : 0.4-4.0 mlU/mL \\
\hline Albumin & $4.2 \mathrm{~g} / \mathrm{dL}$ & $3.4-5.0 \mathrm{~g} / \mathrm{dL}$ \\
\hline ANA & Negative & \\
\hline Serum ceruloplasmin & 22 mg/dL & $20-35 \mathrm{mg} / \mathrm{dL}$ \\
\hline ASO titer & Negative & Less than $200 \mathrm{lU} / \mathrm{mL}$ \\
\hline Iron & 78 ug/dL & Males : 59-158 ug/dL \\
\hline TIBC & 232 ug/dL & Males : 228-428 ug/dL \\
\hline Ferritin & $79.7 \mathrm{ng} / \mathrm{mL}$ & Males : $30-400 \mathrm{ng} / \mathrm{mL}$ \\
\hline RBS (on presentation) & $453 \mathrm{mg} / \mathrm{dL}$ & $80-140 \mathrm{mg} / \mathrm{dL}$ \\
\hline
\end{tabular}




\section{Cureus}

HbA1c ( on presentation )

HbA1c ( on follow up )
$15.13 \%$

$8.24 \%$
Normal $<5.7 \%$ Pre diabetics 5.7-6.4 \% Diabetics $>6.5 \%$

Normal $<5.7 \%$ Pre diabetics 5.7-6.4 \% Diabetics $>6.5 \%$

\section{TABLE 1: Blood investigations with results.}

MCV: mean corpuscular volume, ESR: erythrocyte sedimentation rate, HDL: high-density lipoprotein, LDL: low-density lipoprotein, VLDL: very low density lipoprotein, TSH: thyroid stimulating hormone, ANA: antinuclear antibody, ASO: antistreptolysin O, TIBC: total iron binding capacity, RBS: random blood sugar, HbA1c: glycated hemoglobin, SGPT: serum glutamic-pyruvic transaminase, SGOT: serum glutamic-oxaloacetic transaminase.

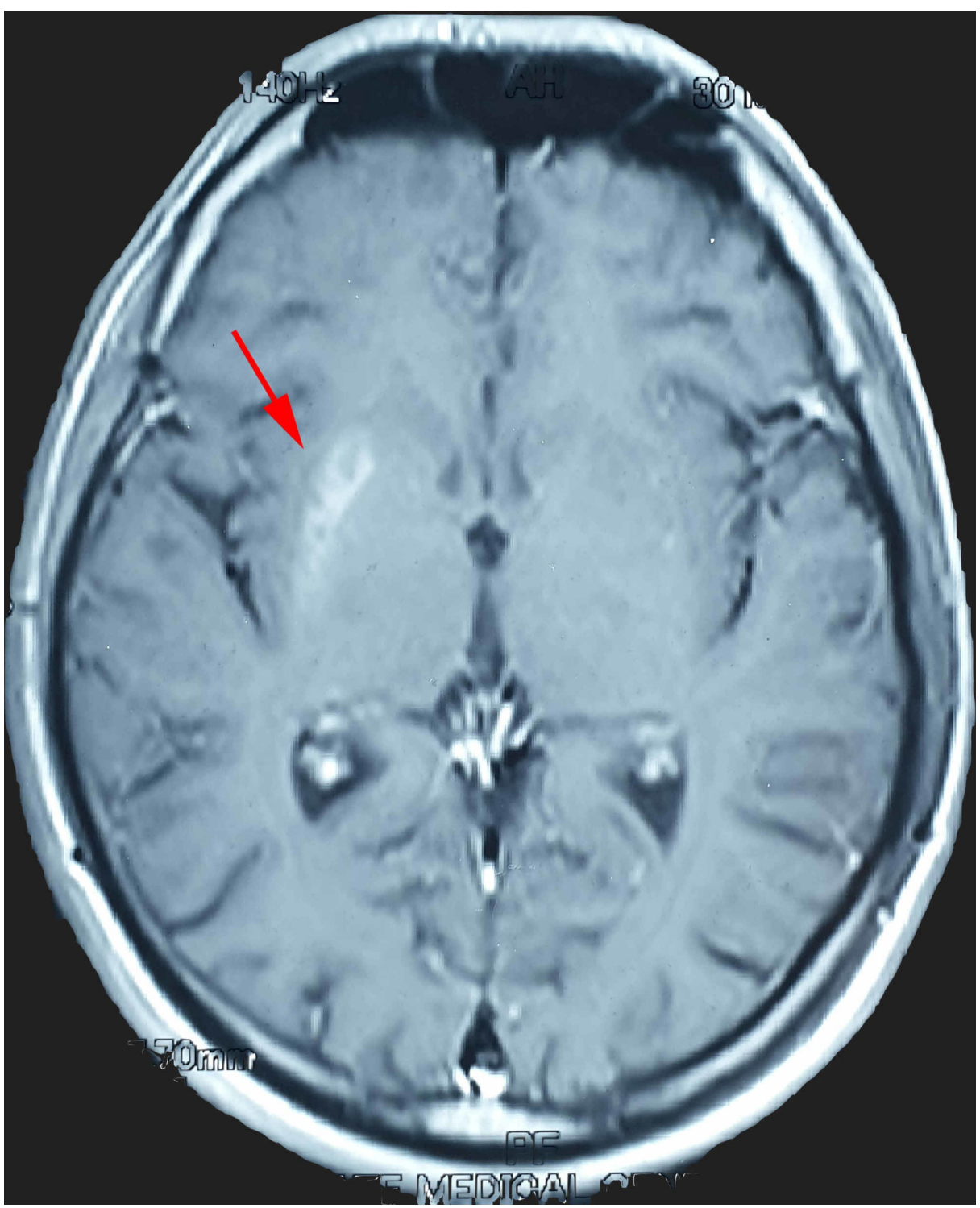

FIGURE 1: T1 Weighted MRI brain image.

Arrow points toward right-sided basal ganglia lesion.

\section{Discussion}

Hyperglycemic-hemichorea was first reported in 1960 [4]. Hyperglycemia is the most common metabolic condition to cause chorea [5]. It is more common in females and the Asian population, but it does exist in other ethnicities [6-7]. The Asian population prevalence of this disorder is probably related to their genetics [5]. Older age is a risk factor, but the younger population has suffered it too [7], as in our patient.

Hyperglycemic-hemichorea involves an upper limb more than a lower limb. It manifests on one side of the body, but bilateral extremities can be affected, and rarely head and trunk are also involved [7]. Typically, it is 
diagnosed on clinical and radiographic findings: uncontrolled blood sugars with hemichorea, and lesions on basal ganglia on T1-weighted MRI brain images. Hyperintense lesion on T1 weighted MRI images is not specific to hyperglycemic-hemichorea and can occur in other central nervous system (CNS) pathologies, e.g. tuberous sclerosis, chronic hepato-encephalopathy, Tay-Sachs disease [8]. When radiographic findings are present, they are found on the contralateral side of patient symptoms, but imaging features are sometimes absent [5]. In bilateral limbs involvement, bilateral basal ganglia imaging lesions have been reported [9]. Lesion on MRI resolves in six months' time after correction of hyperglycemia [10]. Moreover, Putamen is the most commonly involved site with or without the involvement of other regions of basal ganglia, but caudate and globus pallidus are almost never affected alone [9].

To date, the specific mechanism of the disease process is not clear. It has been thought to be multifactorial. Metabolic changes due to hyperglycemia resulting in a decrease in gamma aminobutyric acid (GABA) level are believed to cause this disorder, but it is not clear, why metabolic derangement affects one side of basal ganglia in most patients but not on both sides. Other theories suggest the cause being hyperglycemic hyperviscosity induced ischemia, petechial hemorrhages, calcification, and/or reactive astrocytosis [8-9, 11].

Management of hyperglycemic-hemichorea includes intravenous hydration and insulin therapy. Patients with disabling symptoms should be prescribed dopamine receptor blocking agent (e.g. haloperidol) [7]. Haloperidol is most effective while in some cases neuroleptics or antiseizure agents have shown partial effect or no effect at all in controlling symptoms [2]. In some studies, patients responded better with sugar control alone but hemichorea vanished completely with sugar control and haloperidol combination therapy [9].

\section{Conclusions}

Young patients presenting with hemichorea should be looked for hyperglycemia as possible etiology for their ongoing illness; as chorea in the context of hyperglycemia is a rare, but reversible occurrence.

Hyperglycemic-hemichorea can be better managed with insulin and haloperidol. Further studies are needed to best understand the pathophysiology, female predisposition, and more incidences in the Asian population.

\section{Additional Information \\ Disclosures}

Human subjects: Consent was obtained by all participants in this study. Conflicts of interest: In compliance with the ICMJE uniform disclosure form, all authors declare the following: Payment/services info: All authors have declared that no financial support was received from any organization for the submitted work. Financial relationships: All authors have declared that they have no financial relationships at present or within the previous three years with any organizations that might have an interest in the submitted work. Other relationships: All authors have declared that there are no other relationships or activities that could appear to have influenced the submitted work.

\section{References}

1. Kranick SM, Price RS, Prasad S, Hurtig HI: Clinical Reasoning: a 52-year-old woman with subacute hemichorea. Neurology. 2008, 71:59-62. 10.1212/01.wnl.0000334759.72146.39

2. Ryan C, Ahlskog JE, Savica R: Hyperglycemic chorea/ballism ascertained over 15 years at a referral medical center. Parkinsonism Relat Disord. 2018, 48:97-100. 10.1016/j.parkreldis.2017.12.032

3. Chen C, Zheng H, Yang L, Hu Z: Chorea-ballism associated with ketotic hyperglycemia . Neurol Sci. 2014, 35:1851-1855. 10.1007/s10072-014-1968-1

4. Bedwell SF: Some observations on hemiballismus. Neurology. 1960, 10:619. 10.1212/WNL.10.6.619

5. Lee S-H, Shin J-A, Kim J-H, et al.: Chorea-ballism associated with nonketotic hyperglycaemia or diabetic ketoacidosis: characteristics of 25 patients in Korea. Diabetes Res Clin Pract. 2011, 93:80-83. 10.1016/j.diabres.2011.05.003

6. Shafran I, Greenberg G, Grossman E, Leibowitz A: Diabetic striatopathy-does it exist in non-Asian subjects?. Eur J Intern Med. 2016, 35:51-54. 10.1016/j.ejim.2016.05.026

7. Ondo WG: Hyperglycemic nonketotic states and other metabolic imbalances. Handbook of Clinical Neurology. Elsevier, Amsterdam; 2011. 100:287-291. 10.1016/B978-0-444-52014-2.00021-5

8. Raza HK, Jing J, Cui G, et al.: Hemichorea caused by nonketotic hyperosmolar state: a case report and review of the literature. Somatosens Mot Res. 2017, 34:44-46. 10.1080/08990220.2016.1278205

9. Oh S-H, Lee K-Y, Im J-H, Lee M-S: Chorea associated with non-ketotic hyperglycemia and hyperintensity basal ganglia lesion on T1-weighted brain MRI study: a meta-analysis of 53 cases including four present cases. J Neurol Sci. 2002, 6:10.1016/S0022-510X(02)00133-8

10. Lin J-J, Lin G-Y, Shih C, Shen W-C: Presentation of striatal hyperintensity on T1-weighted MRI in patients with hemiballism-hemichorea caused by non-ketotic hyperglycemia: report of seven new cases and a review of literature. J Neurol. 2001, 248:750-755. 10.1007/s004150170089

11. Goh L, Chinchure D, Lim T: Clinics in diagnostic imaging (166). Singapore Med J. 2016, 57:161-165. 10.11622/smedj.2016052 